\title{
Lethal Serotonin Syndrome After Methylone and Butylone Ingestion
}

\author{
Brandon J. Warrick • John Wilson - Matthew Hedge • \\ Scott Freeman • Karen Leonard • Cynthia Aaron
}

Published online: 9 December 2011

(C) American College of Medical Toxicology 2011

\begin{abstract}
Introduction A new generation of designer phenethylamines have emerged and aggressively marketed as "legal highs." The drugs are labeled "not for human consumption" to avoid widespread recognition and prosecution under the existing analog drug laws. The newest generation includes methylone and butylone. Methylone and butylone have minor structural changes and similar pharmacodynamics properties to scheduled drugs. Case Report We report a case of a healthy 24-year-old who ingested a capsule containing methylone and butylone sold as "Ecstasy" at a concert. The patient presented to the emergency department, comatose febrile, tachycardic, tachypnic, and hypertensive. On exam, she was diaphoretic, tremulous, hyperreflexic, and had sustained clonus. The patient was aggressively cooled, and despite maximal supportive care, the patient progressed to multi-system organ failure and ultimately expired. We obtained and analyzed both her urine and a capsule found on her person similar to the capsules ingested. In both samples, laboratory analysis identified only methylone and butylone.
\end{abstract}

B. J. Warrick $\cdot$ M. Hedge $\cdot$ C. Aaron

Children's Hospital of Michigan Poison Control Center,

4707 St. St Antoine Ave, Suite 302,

Detroit, MI 48201, USA

J. Wilson $\cdot \mathrm{K}$. Leonard

William Beaumont Hospital,

Royal Oak, MI, USA

B. J. Warrick $(\varangle) \cdot$ M. Hedge $\cdot$ S. Freeman

Department of Emergency Medicine, Wayne State University,

Detroit, MI, USA

e-mail: brandon_warrick@hotmail.com

S. Freeman

Detroit Receiving Hospital,

Detroit, MI, USA
Conclusion This is the first reported death for methylone or butylone and the first human or animal ingestion of butylone. Clinicians and public health officials should work together as new designer drugs emerge.

Keywords Methylone · Butylone $\cdot$ Bath salts $\cdot$ Synthetic phenethylamines $\cdot$ Intoxication $\cdot$ Death

\section{Introduction}

A new generation of designer phenethylamines has emerged and was being aggressively marked as "legal alternatives" to "Ecstasy" [methylenedioxymethamphetamine (MDMA)] or methamphetamine. A significant increase in synthetic phenethylamine intoxications have been reported since 2010 [1, 2]. Included in synthetic phenthylamines is methylone and butylone. These substances are distributed primarily over the internet but frequently encountered in convenience stores and "head shops." They have escaped prosecution by law enforcement and the DEA by labeling products "not intended for human consumption" and marketed as bath salts or other non-ingestable products [2]. More recently, the DEA has temporarily scheduled methylone as a schedule I agent.

We present a 24-year-old female who ingested two capsules containing methylone and butylone, sold as "Ecstasy" resulting in multi-organ failure and mortality. The available literature on methylone and butylone is also reviewed.

\section{Case Report}

A healthy 24-year-old female with a history of psoriasis presented to the ED after ingesting two capsules of 
"Ecstasy" at a concert (Fig. 1). Medics found her unconscious with a heart rate of 132 and a blood pressure 80/ $60 \mathrm{mmHg}$. EMS administered $10 \mathrm{mg}$ of intravenous diazepam for apparent seizure activity. Although she experimented with marijuana and cocaine in the past, she was not a chronic abuser.

In the $\mathrm{ED}$, the patient was nonverbal and withdrew to pain. Temperature was $41.8^{\circ} \mathrm{C}$ orally, pulse $158 \mathrm{bpm}$, respirations $34 \mathrm{bpm}$, blood pressure of 101/61 $\mathrm{mmHg}$, and $\mathrm{O}_{2}$ saturation of $100 \%$ on $100 \% \mathrm{O}_{2}$. Pupils were $6 \mathrm{~mm}$ and minimally reactive; mucus membranes were moist with a mild increase in secretions. Other than tachycardia and tachypnea, the heart, lungs, and abdomen were unremarkable. Skin was hot and diaphoretic. The patient was comatose, withdrawing symmetrically to pain, did not open her eyes, but did make incomprehensible sounds. Tremors were noted in the upper extremities with increased tone and bilateral ankle clonus.

She was fluid resuscitated, mechanically ventilated, and externally cooled with ice packs. Myoclonus was initially controlled by $2 \mathrm{mg}$ of intravenous lorazepam followed by $32 \mathrm{mg}$ of midazolam administered between 15 and $45 \mathrm{~min}$ post presentation. Although benzodiazepines decreased myoclonus, they did not fully extinguish it. Non-depolarizing neuromuscular blockers were used to stop all muscle activity to control the hyperthermia. Three hours after neuromuscular blockade, core temperature decreased to $37.7^{\circ} \mathrm{C}$. Four hours after arrival, vital signs were BP 147/83 $\mathrm{mmHg}$, pulse of 130 , and temperature of $37.1^{\circ} \mathrm{C}$. No additional paralytics were given.

Initial ECG showed sinus tachycardia with a rate of 159 bpm, QRS $108 \mathrm{~ms}$, QTc $488 \mathrm{~ms}$, without ischemic changes. Initial laboratory results are detailed in Table 1. Urine for GC-MS was sent but results were unavailable for $24 \mathrm{~h}$.

Shortly after hyperthermia was controlled, she developed posterior epistaxis and oozing from IV sites. Repeat coagulation tests were consistent with DIC. A posterior nasal pack

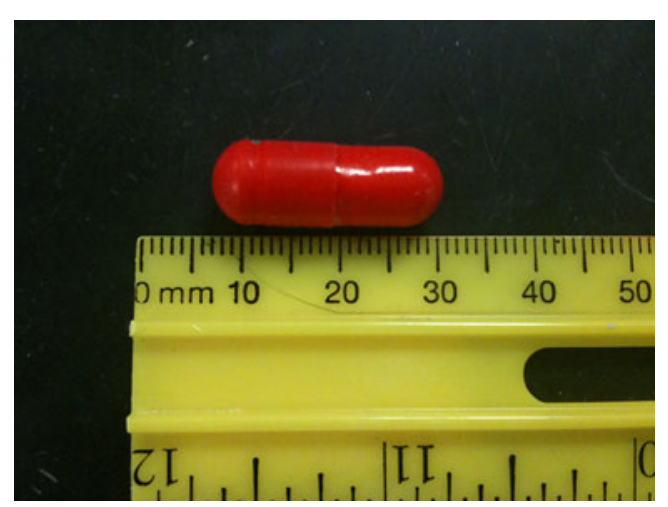

Fig. 1 Capsule obtained and analyzed
Table 1 Laboratory results

\begin{tabular}{lll}
\hline Labs & Initial & $12 \mathrm{~h}$ \\
\hline $\mathrm{pH}$ & 7.31 & 7.49 \\
$\mathrm{pCO} 2$ & $35 \mathrm{mmHg}$ & $30 \mathrm{mmHg}$ \\
$\mathrm{pO} 2$ & $230 \mathrm{mmHg}$ & $67.6 \mathrm{mmHg}$ \\
$\mathrm{Na}$ & $140 \mathrm{mEq} / \mathrm{L}$ & $148 \mathrm{mEq} / \mathrm{L}$ \\
$\mathrm{K}$ & $5.0 \mathrm{mEq} / \mathrm{L}$ & $2.4 \mathrm{mEq} / \mathrm{L}$ \\
Cl & $105 \mathrm{mEq} / \mathrm{L}$ & $116 \mathrm{mEq} / \mathrm{L}$ \\
Bicarb & $23 \mathrm{mEq} / \mathrm{L}$ & $15 \mathrm{mEq} / \mathrm{L}$ \\
BUN & $11 \mathrm{mg} / \mathrm{dL}$ & $22 \mathrm{mg} / \mathrm{dL}$ \\
Crt & $1.9 \mathrm{mg} / \mathrm{dL}$ & $3.0 \mathrm{mg} / \mathrm{dL}$ \\
Glucose & $198 \mathrm{mg} / \mathrm{dL}$ & $126 \mathrm{mg} / \mathrm{dL}$ \\
Acetaminophen & $<10 \mathrm{mcg} / \mathrm{ml}$ & \\
ASA & $<5 \mathrm{mg} / \mathrm{dL}$ & $366 \mathrm{Units} / \mathrm{L}$ \\
AST & $26 \mathrm{Units} / \mathrm{L}$ & $138 \mathrm{Units} / \mathrm{L}$ \\
ALT & $19 \mathrm{Units} / \mathrm{L}$ & $926 \mathrm{Units} / \mathrm{L}$ \\
CPK & $152 \mathrm{Units} / \mathrm{L}$ & $20.3 \mathrm{ng} / \mathrm{mL}$ \\
Troponin I & $0.875 \mathrm{ng} / \mathrm{mL}$ & $>11.49$ \\
INR & 1.04 & $>200$ \\
APTT & $23.6 \mathrm{~s}$ & $5,500 / \mathrm{mm} 3$ \\
WBC & $9,800 / \mathrm{mm} 3$ & $10.9 \mathrm{~g} / \mathrm{dL}$ \\
Hemoglobin & $14.5 \mathrm{~g} / \mathrm{dL}$ & $84,000 / \mathrm{mm} 3$ \\
Platelets & $200,000 / \mathrm{mm} 3$ & Undetectable \\
Fibrinogen & & \\
\hline & & \\
\hline
\end{tabular}

was placed and she was transfused with fresh frozen plasma, packed red blood cells, and platelets to obtain hemostasis.

Ten hours post-admission, the patient developed pulseless electrical activity arrest from an unclear etiology. Spontaneous circulation returned within $90 \mathrm{~s}$ of CPR and $1 \mathrm{mg}$ of epinephrine, but she required multiple pressors (norepinephrine, vasopressin, and dopamine). On repeat examination, clonus, hyperreflexia, and tremor had resolved. Her coagulopathy did not respond to treatment. Repeat lab values showed multisystem organ failure (Table 1). Given the poor prognosis, the family and care team agreed to withhold CPR if the patient's condition deteriorated.

Over the next $24 \mathrm{~h}$, her hemodynamics and coagulopathy improved. However, she developed ARDS and renal failure. Despite optimal ventilation, hypoxemia, and lactic acidosis worsened and she expired $48 \mathrm{~h}$ after presentation.

\section{Drug Analysis}

The patient purchased multiple capsules and ingested two capsules according to her friends. A capsule found in the patient's possession and her urine were analyzed and compared to pure analytical reference standards obtained from Cerilliant Corporation (Catalog \#M-140, B-045 Round 
Rock, TX, USA) at concentrations of $1 \mathrm{mg} / \mathrm{mL}$ in methanol. One-microliter sample injection provided the reference response. Two milliliters of the patient's urine was extracted into dichloromethane at a basic $\mathrm{pH}$, the organic fraction was removed and evaporated to dryness under an airstream at $40^{\circ} \mathrm{C}$, and reconstituted with $25 \mu \mathrm{L}$ of ethyl acetate. One microliter was injected into an Agilent 5972A MSD (Agilent, Andover PA, USA) GC/MS. A small portion of the submitted capsule was weighed and dissolved in $10 \mathrm{~mL}$ of methanol. One microliter was injected consistent with reference standards and patient samples and the instrument TIC response used to calculate the capsule dose by relative peak area.

The powder mass was $619 \mathrm{mg}$. Analysis revealed the $422 \mathrm{mg}$ of methylone and $53 \mathrm{mg}$ of butylone. GC/MS of the urine was positive for methylone and butylone and negative for other drugs of abuse including THC and cocaine. Autopsy revealed evidence of a generalized coagulopathy, fatty liver, and anoxic encephalopathy. According the medical examiner, the cause of death was serotonin syndrome secondary to methylone and butylone.

\section{Discussion}

This patient presented to the Emergency Department hyperadrenergic with serotonin excess. She was hyperthermic with uncontrolled muscle activity and possible seizure after ingesting two capsules sold as "Ecstasy." Methylone and butylone were confirmed by laboratory analysis in the capsule and patient's urine.

We reviewed the literature on methylone and butylone through PubMed, Google Scholar, and unorthodox websites, using the search terms methylone or butylone. Pharmacokinetics and pharmacodynamic information is minimal for methylone and we were unable to find any data on butylone. Methylone is the beta-keto analogue of methylenedioxymethamphetamine (MDMA) and referred as bk-
MDMA or M1. Butylone is the beta-keto analogue of methylbenzodioxylbutanamine (MBDB) referred as bk-MBDB or B1 (Fig. 2). The only published dose of methylone was $120 \mathrm{mg}$ mixed with $76 \mathrm{mg}$ 5-MeO-MIPT (N-isopropyl-5methoxy-N-methyl-tryptamine) [3]. On-line first person accounts indicate $100-250 \mathrm{mg}$ is a common dose of methylone. A "heavy" dose is greater than $250 \mathrm{mg}$. Writers describe drug effect onset at 15-30 min with duration of $2-3.5 \mathrm{~h}$ but $6-24 \mathrm{~h}$ to return to "normal," oral doses are slightly less effective than equivalent IV doses [4]. There are no published human ingestions of butylone in the medical literature. On-line bloggers report doses of 150-250 mg [4].

The pharmacodynamic literature is limited to one in vivo report, two case reports, and numerous "trip reports" for methylone [3, 5-7]. Similar to MDMA, MBDB, and other phenethylamines, methylone, and butylone are expected to increase levels of serotonin, dopamine, and norepinephrine [7]. In vitro, methylone is threefold less potent than MDMA at inhibiting platelet serotonin accumulation. Methylone is equipotent to MDMA for inhibition of dopamine and norepinephrine transporters [6]. Reports from on-line blogs and forums suggest the psychotropic effects of butylone and methylone are similar although users report the ability to differentiate butylone from methylone, MDMA and MDBD [4].

In both case reports involving methylone, the patients had euphoria, dilated pupils, and diaphoresis [3,5]. Only one report provides a detailed physical examination consistent with serotonin excess complicated by a seizure [3]. The authors hypothesized the seizure resulted from hyponatremia secondary to water intoxication. Our case met the Hunter criteria for serotonin syndrome with hyperreflexia, tremor, muscle rigidity, spontaneous clonus, and temperature $>38^{\circ} \mathrm{C}[8,9]$. Further supporting the diagnosis of serotonin syndrome is resolution of hyperreflexia and myoclonus within $24 \mathrm{~h}$. Since it is not possible to differentiate the presence of excess dopamine or norepinephrine by
Fig. 2 Beta-keto analogue of methylenedioxymethamphetamine (MDMA) and methylbenzodioxylbutanamine
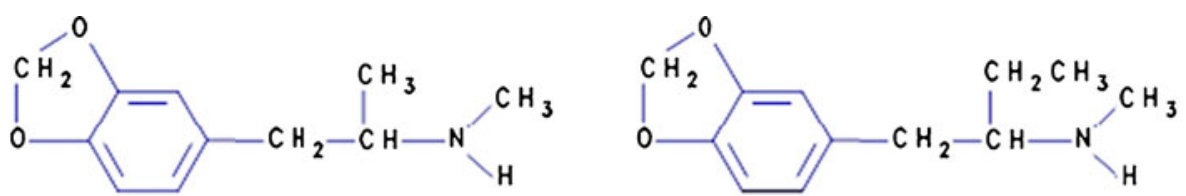

METHYLENEDI OXYMETHAMPHETAMINE.

MOMA<smiles>CNC(C)C(=O)c1ccc2c(c1)OCO2</smiles>

METHYLONE, BK-MOMA
METHYLBENZODIOXOLYLBUTANAMINE, MBDB

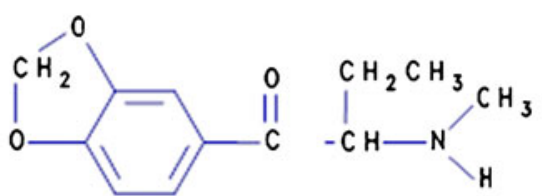

BUTYLONE, BK-MBDB 
physical exam, we assume both cases had an excess of dopamine and norepinphrine based on consistency with in vivo data.

Our patient died after ingesting two capsules despite expeditious treatment. Based on analytic evidence from a single capsule, we suspect she ingested $844 \mathrm{mg}$ of methylone plus $106 \mathrm{mg}$ of butylone. The dose the patient ingested was substantially over what has been reported as a "normal" dose. However, we cannot confirm this dose since any illicitly marketed drug has substantial variability in purity and concentration. Another factor that may have contributed to her poor outcome was the unknown duration of symptoms prior to presentation to the hospital. Although cooling measures were immediately begun in the ED, the patient developed DIC and had a brief pulseless electrical activity arrest. While she was successfully resuscitated from the arrest, multi-organ system failure progressed despite aggressive supportive care.

\section{Conclusion}

Methylone and butylone are emerging drugs of abuse and this is the first report to highlight a death from either substance. While this case is fairly typical for severe serotonin syndrome and/or sympathetic intoxication, it highlights the potential lethality of these drugs. The case underlines our need to better understand the pharmacology mechanism of action, and optimal treatment of synthetic phenethylamine intoxication. While serving as surveillance for emerging drugs of abuse, poison centers need to proactively educate healthcare providers, public health officials, and the community regarding the dangers of these readily available designer phenethylamines.

\section{References}

1. Emergency department visits after use of a drug sold as "bath salts"Michigan, November 13, 2010-March 31, 2011 (2011) MMWR. 60 (19):624-627

2. Center, U.S.D.o.J.N.D.I. Synthetic cathinones (bath salts): an emerging domestic threat. July 2011

3. Shimizu E, Watanabe H, Kojima T, Hagiwara H et al (2007) Combined intoxication with methylone and 5-MeO-MIPT. Prog Neuropsychopharmacol Biol Psychiatry 31(1):288-291

4. Methylone. [cited 2011 August 15]; Available from: http://www. erowid.org/chemicals/methylone/methylone.shtml

5. Boulanger-Gobeil C, St-Onge M, Laliberte M, Auger PL (2011) Seizures and hyponatremia related to ethcathinone and methylone poisoning. J Med Toxicol. doi:10.1007/s13181-011-0159-1

6. Cozzi NV, Sievert MK, Shulgin AT et al (1999) Inhibition of plasma membrane monoamine transporters by beta-ketoamphetamines. Eur J Pharmacol 381(1):63-69

7. Jacob P, Shulgin AT (1994) Structure-activity relationships of the classic hallucinogens and their analogs. NIDA Res Monogr 146:7491

8. Boyer EW, Shannon M (2005) The serotonin syndrome. N Engl J Med 352(11):1112-1120

9. Dunkley EJ, Isbister GK, Sibbritt D et al (2003) The Hunter serotonin toxicity criteria: simple and accurate diagnostic decision rules for serotonin toxicity. QJM Monthly J Assoc Physicians 96(9):635642 